Division of Epidemiology and Pharmacoepidemiology of Rheumatic Diseases from Ayumi Pharmaceutical Co. Ltd., Bristol Meyers Squib, Chugai Pharmaceutical Co. Ltd., Nippon Kayaku Co. Ltd., Taisho Toyama Pharmaceutical Co. Ltd., Mitsubishi Tanabe Pharma Corp., and with which TWMU paid the salary of $\mathrm{MH}$. $\mathrm{MH}$ has also received research grants from AbbVie Japan GK, Eisai Co. Ltd., Takeda Pharmaceutical Co., Ltd., and Teijin Pharma Ltd., Hisashi Yamanaka Grant/research support from: AbbVie, Eisai, Bristol-Meyers, Novartis, Behringer, Astellas, Kaken, Nippon-Shinyaku, Pfizer, UCB, Ayumi, Ono, Daiichi-Sankyo, Taisyo-Toyama, Takeda, Tanabe-Mitsubishi, Chugai, Teijin Pharma, Torii, YLbio, Speakers bureau: Bristol-Meyers, Astellas, Pfizer, Daiichi-Sankyo, Takeda, TanabeMitsubishi, Chugai, Teijin Pharma, YLbio

DOI: 10.1136/annrheumdis-2019-eular.4439

\section{AB0555 1 POTENTIAL ROLE OF PAROTID ELASTOGRAPHY IN DIAGNOSIS AND CLASSIFICATION OF PATIENTS WITH PRIMARY SJÖGREN'S SYNDROME}

Hasan Satıș ${ }^{1}$, Betül Nur Demir ${ }^{2}$, Reyhan Bilici Salman ${ }^{1}$, Esra Temel ${ }^{2}$, Hakan Babaoglu ${ }^{1}$, Nuh Atas ${ }^{1}$, Aslıhan Avanoglu Güler ${ }^{1}$, Hazan Karadeniz', Emetullah Cingil' ${ }^{2}$, Abdurrahman Tufan ${ }^{1}$, Mehmet Akif Ozturk $^{1}$

Seminur Haznedaroglu', Berna Göker'. ' ${ }^{1}$ Gazi University Faculty of Medicine, Rheumatology, Ankara, Turkey; ${ }^{2}$ Gazi University Faculty of Medicine, Radiology, Ankara, Turkey

Background: Despite the improvements in classifying patients with primary Sjögren's syndrome with usage of the new 2016 ACR/EULAR classification criteria, there remains to be a need for improvement and investigating the value of new modalities in diagnosing as well as classifiying these patients.

Objectives: to investigate potential role of parotid elastography in diagnosis and classification of patients with primary Sjögren's syndrome (pSs)

Methods: This is a cross sectional analysis of patients with primary Sjögren's syndrome followed up in our out-patient Rheumatology clinic. We performed chart reviews and retrospectively investigated the available data on files to search whether or not our clinically diagnosed patients satisfied the 2002 AEG and/or 2016 ACR/EULAR criteria sets. Ultrasonographic and elastographic evaluation of parotid and submandibular glands bilaterally were performed on consecutive patients with clinical diagnosis of pSs and contributions of these findings to classification criteria sets were interpereted

Results: There were 95 pSs patients and 30 healthy gender and age matched controls. Strain ratio, shearwave velocity and Pascal values of the glands were examined. Parotid strain ratio, submandibular velocity and submandibular pascal values were statistically significantly different compared to healthy controls (Table).\%86 of patients considered clinically as Sjögren syndrome satisfied 2016 ACR/EULAR (criteria patients) and\% 84 satisfied 2002 AER classification criteria. We grouped patients with respect to parotid strain ratio taking 1.0875 as the cut-off value. Those patients who did not satisfy 2016 ACR/EULAR criteria, but clinically diagnosed as pSs (non criteria pSs patients), also had significantly higher parotid strain ratio and submandibular velocity compared to healthy controls ( $p: 0,016$ and $p<0,001$ respectively). Interestingly, both criteria and non-criteria $\mathrm{pSs}$ patients had similar parotid strain ratio and submandibular velocity value $(p: 0,892$ and $p: 0,260$, respecitively)

Conclusion: Parotid shear elastography is an easy and nonivasive method and can be a useful tool for the diagnosis and classification of patients with pSs (1)

\section{REFERENCES}

[1] Mossel E, Delli K, van Nimwegen JF, Stel AJ, Kroese FGM, Spijkervet FKL, Vissink A, Arends S, Bootsma H; EULAR US-pSS Study Group. Ultrasonography of major salivary glands compared with parotid and labial gland biopsy and classification criteria in patients with clinically suspected primary Sjögren's syndrome Ann Rheum Dis. 2017 Nov;76(11):1883-1889. doi: 10.1136/annrheumdis-2017-211250

Disclosure of Interests: None declared

DOI: 10.1136/annrheumdis-2019-eular.6036

\section{AB0556} PARTICULARITIES OF PULMONARY HYPERTENSION IN SYSTEMIC LUPUS ERYTHEMATOSUS

sameh sayhi, Nouha Ghriss, Najeh Boussetta, Bilel Arfaoui, Faida Ajili, Nadia Ben Abdelhafidh, Bassem Louzir. Military Hospital of Tunis, Autoimmune Diseases Unit Research: UR17DN02, Tunis, Tunisia

Background: Systemic lupus erythematosus (SLE) is an autoimmune dis ease that primarily affects young women. It is characterized by the production of autoantibodies and immune complexes. Vascular pulmonary involvement has long been considered rare, a consequence of thromboembolic events. It is in fact a proper entity, often of multifactorial mechanism, with spontaneous evolution to pulmonary arterial hypertension (PAH), which makes its gravity

Objectives: The objective of our study is to determine the particuliarities of PAH during SLE.

Methods: We conducted a mono-centric, retrospective and descriptive study of the follow up of patients in the internal medicine department of the Military Hospital of Tunis for LES (diagnosis according to the ARA criteria) between January 2010 and December 2015.

All patients underwent external echocardiography or during their stay in the department

Results: We collected 87 patients diagnosed with SLE. PAH was recorded in 16 patients $(38 \%)$ including 6 men and 10 women with a F/ $\mathrm{M}$ sex ratio of 1.66 . The average age was 37.23 years with extremes ranging from 16 to 70 years old. Clinically, we observed dyspnea in 10 patients $(62 \%)$, chest pain in 7 cases $(43 \%)$, dry cough in 2 cases $(12 \%)$, palpitations in 1 case $(6 \%), \%)$ and right heart failure in 1 case (6\%). At cardiac auscultation, 5 patients were tachycardic (31\%), 5 had a tricuspid systolic murmur and 1 had an irregular rhythm. A burst of B2 in the pulmonary focus was noted in 3 patients $(18 \%)$. Nine of the 16 patients with PAH had electrical signs: five had sinus tachycardia $(31 \%)$, two had signs of right ventricular hypertrophy. A complete arrhythmia with atrial fibrillation was noted in one patient. The chest X-ray showed cardiomegaly in 6 patients (37\%). Among the 16 patients, there was a tricuspid valve insufficiency associated with PAH in 7 patients (43\%), 2 had mitral valve insufficiency $(12 \%), 6$ patients had pericarditis, one patient had endocarditis (6\%) and myocarditis was found in another one (6\%). PAH was isolated in $12 \%$ of cases. In Immunological tests, NAAs were positive in all patients. Three quarters of the patients (12) had native anti-DNA positive $(75 \%)$ and $1 / 4$ of the patients (4) had anti-Sm positive and anti-RNP positive antibodies (25\%). The complement was consumed in 5 cases $(31.2 \%)$. Anti-phospholipid antibodies were noted in 4 cases (25\%). Added to non-specific measures (smoking cessation, elimination of intense physical effort ...) adopted for all patients, oxygen therapy was indicated in four patients. Diltiazem $180 \mathrm{mg} /$ day vasodilator therapy was prescribed in 3 patients. Effective anti-vitamin $\mathrm{K}$ anticoagulation was prescribed in a patient with severe PAH at $80 \mathrm{mmHg}$.

Conclusion: Pulmonary arterial hypertension (PAH) is a rare complication of systemic lupus erythematosus, its prevalence varies from 0.5 to $17.5 \%$ depending on the series. SLE is the second leading cause of PAH in connective tissue disease after systemic sclerosis. This vascular involvement is essential for the prognosis and is an important evolutionary step in the management.

Disclosure of Interests: None declared

DOI: 10.1136/annrheumdis-2019-eular.8162

\section{AB0557 NON-CORONARY CARDIAC MANIFESTATIONS OF SYSTEMIC LUPUS ERYTHEMATOSUS IN ADULTS}

Nouha Ghriss, sameh sayhi, Najeh Boussetta, Nour El Houda Gueddich, Faida Ajili, Nadia Ben Abdelhafidh, Bassem Louzir. military hospital, autoimmune diseases unit research: UR17DN02, tunis, Tunisia

Background: Systemic lupus erythematosus (SLE) is a common chronic multi-system autoimmune disorder of unknown etiology causing injury to many organ Systems. It predominantly affects young women. Cardiac manifestations develop in the majority of patients with SLE at some time during the course of their disease.

Objectives: The aim of our study is to assess cardiac abnormalities in patients with systemic lupus erythematosus (SLE) by echocardiography and to compare the 2 groups of patients with and without cardiac manifestations.

Methods: We have performed a transversal, descriptive study of SLE patients hospitalized in the Internal Medicine department at the Military Hospital of Tunis between January 2016 and June 2018. Diagnosis of SLE was made according to the criteria of ACR. All patients underwent a cardiac ultrasound externally or during their stay in our department. 